\title{
Discussion on bolt support technology in coal mine roadway
}

\author{
Ming Li \\ School of energy and safety, Anhui University of Science and Technology, Huainan, Anhui, \\ 232001, China \\ sanmao1219@126.com
}

Keywords: Coal mine; roadway; bolt support

Abstract. To create a modernization mine of safe and efficient production, the premise is that must be to ensure safety, economy, stability of the roadway support, and bolt support in coal roadway supporting systems plays an important role, in order to make the bolt support can better service for our modern mine. In this paper, Firstly, the supporting principle of bolt support and the composition of bolt support and the application of each component are introduced. Secondly, Combined with my practical work experience, the method of determining the parameters of bolt support and the method of designing anchor support are analyzed, Finally, the construction and inspection of bolt support are summarized, in order to provide reference for the related workers.

\section{Introduction}

Roadway supporting technology is a key technology in mine construction and coal mining, safe and reasonable and effective roadway support is a necessary condition to ensure the high efficiency and high yield of the mine. Bolt support has many advantages, such as good supporting effect, high efficiency, low cost and so on, It is widely used in coal mining, and bring huge technical and economic benefits to coal mining enterprises, bolt support has become one of the main development directions of roadway support.

\section{Principle of bolt support}

Rock bolt is a kind of anchor bolt system installed in the surrounding rock system. The main purpose of bolt support in roadway is reinforce the roadway to maintain the stability of the roadway. Bolt support is that bolt hole is hit into the surrounding rock after the excavation roadway, and then the bolt is installed in the bolt hole to support the tunnel. The development course of the bolt support is mainly from low strength bolt, step by step to high strength anchor, and finally develop into high strength anchor bolt.

Bolt support is mainly through the anchor zone of the surrounding rock in the compression state, to better prevent the surrounding rock deformation and tensile phenomenon, the strength of the surrounding rock is strengthened to ensure the integrity of the surrounding rock. The secondary bearing structure can be produced in the anchorage zone by the bolt support, the stress condition of surrounding rock is improved effectively, it can effectively prevent the occurrence of anchorage zone outside the strata separation phenomenon. In order to make the whole stiffness of the bolt support to be able to reach the standard, when the bolt is supported in the roadway, first, the strength of the anchor itself must be up to the standard, Secondly, we should according to the actual situations of surrounding rock scientifically and reasonably determine the prestress of anchor bolt, the concrete can be achieved through the use of pallets, steel, metal mesh to spread prestress of anchor, and then make the area of the rock bolt supporting the surrounding rock reached the maximum. If the surrounding rock structure is more complicated, a combined support system with a extension amount of high strength prestressed anchor bolt should be used, the functions of the bolt can be divided into two aspects. First, it can strengthen the ability of connecting the secondary bearing structure of anchor rod with deep surrounding rock, and then improves the stability of the secondary load bearing structure. Second, the discontinuity between the shear resistance is reinforced by increasing the pretightening force of bolt, eventually the overall strength of surrounding rock is greatly improved. In order to 
effectively reduce the amount of roadway maintenance, reduce the cost of the two bolt support, when the bolt is supported, as far as possible to make a support to achieve the desired requirements.

\section{Bolt supporting structure and the function of each component}

Bolt supporting structure. Anchor rod, plate, nut, anchor agent, and metal mesh bolting are the main components of the system. The scientific and rational combination of these components will eventually enable the effect of bolt support .

Role of anchor rod. The main role of the bolt body is the tensile and shear resistance, and it has a very small effect on the bending and compression.

Role of splint. In combination of bolt support, one of the most important component is bolt plate,the pallet plays a very important role in the whole bolt support system. Its function can be roughly divided into the following two aspects. First, pallet will closely fit the roadway surrounding rock by pressing force nut, the coal rock mass around the anchor bolt is also affected by the pre tightening force, and then it is good to improve the stress of surrounding rock, effectively prevent the occurrence of rock layer, sliding and cracking phenomenon, to achieve the purpose of active and timely support. Second, If the surrounding rock has a deformation, plate will be the first to be load, then acting on the bolt body. This will increase the resistance of the anchor, in order to better restrain the deformation of surrounding rock

Role of anchoring agent. The main effect of the anchoring agent is bonding the wall rock of borehole and the rock bolt, in this way, the supporting effect of the bolt can reach the best. In addition, the anchoring agent also has the effect of shear and tensile strength, it can be combined with the anchor to reinforce surrounding rock.

Role of anchor net. The anchor net in the bolt support can make the surrounding rock between the anchor bolt protected, effectively prevent the debris scattered and caved, the anchor net is close to the surface of the roadway, it can make the force of the surface rock has been very good improvement.

\section{Method for determining parameters of rock bolt support.}

Surrounding rock condition and suspension mechanism. The typical mechanism of the suspension structure of layered rock mass is that the unstable rock strata are suspended on the upper stable layer by using the anchor rod. The weight of the unstable rock stratum is the load of the anchor bolt. In general, strong rock strata is at the top of the roof $1 \sim 1.8 \mathrm{~m}$, weak rock strata is the lower part of the top plate, if there is no solid rock in the upper part of the roof, it can replace the function of the fixed rock stratum by using the non broken stable belt or the non pressure arch height.

Composite beam mechanism and surrounding rock condition. In the layered rock structure, the anchoring force of the anchor rod in the axial direction prevente rock separation and relative displacement, it is the use of anchor bolts to combine several thin layers of rock to form a thick layer, forming a combined beam structure. Compared with poor lithify, the bending resistance of composite beams is poor, but it can improve the stability of roadway roof, establishment of relevant parameters of bolt support based on the load condition of composite beam.

Three hinged arch mechanism and surrounding rock condition. In the massive wall rock which is cut by the crack, the rock can be suspended by the anchor bolt to form a stable three hinged arch mechanism. This rock is not only difficult to fall, and the whole loading structure can bear.

\section{Bolt support design method}

The design method of bolt support can be divided into suspension theory, natural balance arch theory, composite beam theory, reinforcement arch theory and dynamic information design method, The natural balance arch theory mainly refers that the relation between the surrounding rock and the surrounding rock is destroyed after mining roadway excavating. The natural equilibrium arch will naturally balance in a certain deep layer, the purpose of stabilizing surrounding rock is achieved by 
studying this balance. Reinforced arch theory refers that cylindrical conical compression zone can be produced in the round under the influence of anchoring force, compression zones produced by multiple anchors are combined together to form a reinforcement arch, this reinforced arch has a certain thickness and larger carrying capacity, its shrinkage is relatively good, so as to support the roadway better.

\section{Construction and inspection of bolt support}

Drilling and installing bolt is the main working procedure of anchor bolt support, drilling should be strictly in accordance with the requirements of the design, the concrete hole position, bore depth and angle should be scientific and reasonable, drilling must be finished before installing the anchor bolt.

In the inspection of anchor support, the depth and diameter of the hole should be matched with the length and diameter of the anchor bolt, to smooth the surface of the rock then Installing pallet, to use a wrench to tighten the nut, so that the prestressed rod is large enough, and carefully check the quality of the anchor itself.

\section{Conclusions}

Shelf, stone masonry beam and rock bolt are the main forms of coal mine roadway support. The shed and stone masonry beam are passive support, the support cost of these support methods is high, the progress is slow, the support effect is not good, so they have been gradually eliminated by the modern mine, and bolt support is a kind of safe, efficient and economical support form, it will be more and more used in the modern mine roadway support, therefore, we should fully understand the supporting principle of bolt support, the composition, the determination method of parameters, design methods, construction and inspection methods, only on the basis of understanding the above informations fully, we can design roadway bolting support Scientific and reasonable.

\section{Acknowledgements}

Financial support for this work was provided by the National Natural Science Foundation of China( No.51274008,51574006,51474006)and the Specialized Research Fund for the Doctoral Program of Higher Education of China (20123415130001) and are gratefully acknowledged. In addition, we wou ld like to thank the anonymous reviewers who have helped to improve the paper.

\section{References}

[1] A.Y. Zhang, X.Chen. Design and Application of Parameters of Bolt Support in Coal Roadway, Coal Mine Support, Vol. 20 (2009) No.2, P.48.

[2] X.S.Zhou, K.Yang, Q.F.Bei. Study on Reliability of Bolt Support in Deep Coal Roadway, Coal Mine Support, Vol. 26 (2006) No.4, P.30.

[3] M.C.He, et al. Theory and Practice of Bolt Support in Coal Mine of China. (Beijing Science Press, China 2004 ).

[4] L.H.Guo, Z.J.Hou, F.F.Gou. Bolt Support in Coal Roadway.(China University of Mining and Technology Press, China 1999 ).

[5] G.T.Song, M.X.Ku. Guide for construction of Bolt Support in Coal Roadway. (Coal Industry Press, China 1999).

[6] H.P. Kang. Research and Practice on Complete Set Technology of Bolt Support in Coal Roadway,Chinese Journal of Rock Mechanics and Engineering, Vol. 24 (2005)No.21,P.3959.

[7] A.M.Yao, S.Sun, Y.F.Liu. The Present Situation and the Development Trend of Anchor Rod Supporting. Journal of North China University of Technology, Vol. 30 (2007) No.2, P.90.

[8] H.T.Zhang. Construction Technology of Bolt Support in Coal Roadway, Coal Technology, Vol. 21 (2006) No.4, P.74. 